\title{
An Overview of Digital Marketing Practices in India
}

\author{
S. Mahalingam ${ }^{1}$, B. Ashokkumar ${ }^{2 *}$ \\ ${ }^{I}$ Professor, Bharathiar School of Management and Entrepreneur Development, Bharathiar University, \\ Coimbatore, India \\ ${ }^{2}$ Research Scholar, Bharathiar School of Management and Entrepreneur Development, Bharathiar University, \\ Coimbatore, India \\ *Corresponding author: ashokdrr3201@gail.com
}

\begin{abstract}
The most popular businesses adopt the Internet, not simply as another advertisement tool or marketing instrument. It is seen as a mechanism for transforming the companies and changing everything about the way computers and mobile devices function to serve their customer better and to connect with their suppliers. In short, digital marketing has sparked a business world revolution by pushing out some old established players and rising new leaders. The winners discover new market possibilities, enhanced ways to develop work and better ways to manage and run their companies. Despite this, the digital marketing entrepreneurs still have to take care of their clients and earn a profit to remain in the business. Web-based business success requires the entrepreneur to strike a balance between creating a digital marketing strategy that utilizes the strength of the Internet and meeting customer expectations of convenience and service. Consumer's present use of mobile devices, social media and search engines have led to developing integrated social -local-mobile strategies (SOLOMO). Entrepreneurs may use the SOLOMO strategy effectively as customers enhance their online activities by extensively using these three methods.
\end{abstract}

Keywords: Advertising, Customer satisfaction, Digital marketing, Digitization, Marketing, Protocol, Social media.

\section{Introduction}

The word technology comes from the Greek word 'technologic' meaning systematic treatment. The Webster's English language offers the most elaborate and comprehensive definition of technology. It is the information division that deals with culture, society, and the world, drawing on artefacts such as industrial arts, engineering, applied science, and pure science. Technology is one of the prim emotive forces of development. If the need for more food, better education, better health care, greater industrial production or more effective transportation and communication, technology plays a decisive role everywhere. It consists of a system of knowledge, skills, experience and organization that is required to produce, utilize and control goods and services. Technology is critical for growth, since it is a resource and producer of new resources. In economic terms, increased use of improved technology "will result in greater quantities of production for given quantities of capital and labour, better products, new products and a wider product range." All these constitute economic growth. It is an important instrument of change in society. Technology perpetuates value systems and its transfer. One of the important determinants of economic and social development of a nation, as well as the success of a firm, is technology. It is among economic growth's most important inputs. Countries that possess superior technology enable their people to earn enhanced incomes through high productivity and, thereby, they enjoy a high standard of living.

The benefits of digital marketing may not be fully utilized if the company is changing incrementally, either by making adoption of digital marketing without organizational changes or by partially implementing some organizational changes which can only lead to significant product losses. In the world of digital marketing, new business models recognize the power of the Internet and empower to customers whether they buy online or offline. The Internet makes pricing more transparent than ever before. Customers may compare the prices of the same or similar goods and services from companies across the globe with only a few mouse clicks or swipes on a smartphone. In the connected economy, the balance of power is shifting to a customer who comparison shops. The first e-commerce transaction took place on August 11 1994, when 'Net Market', a small company established by Daniel Kohn, sold a C.D to a student at Swarthmore College for $\$ 12.48$ plus shipping. From this transaction grew a distribution channel that now accounts for $\$ 304$ billion in annual retail sales. Despite the many benefits the Internet offers, not every small business owner is, however, ready to embrace digital marketing. The blurring of the boundaries among the Internet, social media and the traditional storefronts have changed the way companies interact with their customers. Before launching into digital marketing, entrepreneurs may consider the following issues. Firstly, how a company uses Internet connectivity, and the opportunities that come its way to transforming relationships with its suppliers, customers and other external stakeholders are essential to its success. Success allows an organization to create a strategy to incorporate the Internet into its overall business schemes. The goal should address issues such as website design and 
maintenance, creating and managing a brand name, marketing and promotional strategies, sales and customers service.

\section{The compartmentalization of Digital Marketing Practices}

Advances in emerging technology and creative advances have altered consumer behaviour and marketing strategies. The Internet, the World Wide Web, blogs, search engines, email systems, social media platforms and mobile apps are some of the most disruptive inventions allowed by IT. These innovations have increased the volume and accessibility of digital information by making it ubiquitous (i.e., data can be accessed anywhere, anytime), and have fostered the fast and smooth exchange of information between people and organizations via digital communication channels. (Joel Jarvinen, 2016). In the following section, the various types and forms of digital communication channels are discussed.

\section{A. ICT and the Internet}

In today's business world, the Information and Communication Technology (ICTs) and the Internet have become very important and a powerful weapon in such a way that it is now becoming the 'lifeblood' of industry, without which most companies cannot survive the competitive competitiveness of their operations. The cost of doing business has decreased globally because of the advent of information technology. The ICT has enabled direct communication and established healthy relationships with customers, suppliers and distributors which have been helpful for rapid and efficient service delivery and transactions. This is an essential phenomenon in the global transformation of financial, political and economic life. Various variants of information technology have emerged in recent times such as electronic commerce, electronic marketing, electronic banking, electronic learning etc.

The Internet has different meanings and uses too many people (Roland Acheampong \& Peter Gawk, 2011). According to Violin (1996), Its ability to disseminate vast quantities of information rapidly and efficiently to all forms of stakeholders, including staff, consumers, shareholders and suppliers, makes it considered a technology asset. The Internet is more available and less costly than it has been to date, and the number of internet users is increasing. The use of the Internet in organisations has been the focus of many research studies because of its importance in improving organisation performance. Businesses, big as well as small, have grasped the ability to explore Internet applications to become more profitable and successful. The Internet is said to fundamentally reshape the course of businesses. It is announced and promoted as a technology, which has the potential to profoundly affect how businesses are conducted and how information is accessed. The Internets defined as a network of networks, which interchange data, using a set of communication standards, called the Internet Protocol Suite (IPS), in particular Transport
Control Protocol/ Internet Protocol (TCP/IP). It consists of thousands of computer networks at businesses, universities, and governmental agencies, all linked together by phone lines, microwave transmissions, or fibre optics. The history of the Internet dates back to the early 1960s when the Advanced Research Projects Agency (ARPANET) was founded by the U.S. Department of Defense to connect different military and research institutions. One of its major accomplishments was the creation of the standard protocol, which allowed for the communication of dissimilar computer systems. This protocol, known as TCP/IP (Transmission Control Protocol/ Internet Protocol) remains the most commonly used on the Internet today. During the late 1980s, the National Science Foundation (NSF) used the ARPANET technology to expand its NSFNET - a high-speed backbone network linking campuses and research centres to the NSF's supercomputers. The Internet came to the world's notice in the1990's. Since its inception in the 1960s, the Internet has evolved from communications medium reserved for elite researchers and scientists to a highly sophisticated commercial medium. As public interest exploded in the 1990s, the Internet was opened up to other groups, including individuals and companies. Full commercial Internet connections became available in 1991 with the establishment of the Commercial Internet Exchange. This led to the explosion of commercial sites, which continue to be the most growing component of the Internet. (Japhet eke Lawrence, 2002).

\section{B. Intranet and Extranet}

Both companies and customers have access to most Internet providers on the Internet. Nevertheless, the entrance to sensitive company information is limited to qualified individuals or partners in many E-business applications. If communication is limited to employees inside an organisation, this is referred to as Intranet. If access to an organisation's web services is made available to a few others, but not everyone beyond the organisation, this is an extranet. Whenever a customer logs on to an Internet service such as that for a retailer or online news site, this is in effect an extranet arrangement; Despite this, the term is most regularly used to mean business to the business application where customers or suppliers are given shared access.

\section{E-commerce and E-business}

In 1991, when the Internet was commercialized, e-commerce became possible and since then, many companies have developed their websites. (Roland Acheampong \& Peter Gyawu, 2011). Electronic commerce has been understood as the use of electronic devices such as a computer, telephone, fax, machine, barcode reader, credit cards, automated teller machines, and other electronic devices. Many activities such as order fulfilment, transaction processing system, customer support, etc. are performed through electronic commerce. For example, a customer is said to be participating in electronic commerce if he is swiping a bank card. Many recognised institutions have provided definitions such as UNCTAD has 
defined electronic commerce as doing trade electronically. Other explanations include the process of procuring, selling, and transferring of information through computer networks.

\section{E-commerce defined}

An e-commerce transaction is the selling or purchase of goods or services that are carried out over computer networks using methods explicitly designed to obtain or position the order. These methods order the goods or services, but the online payment and the ultimate delivery of the goods or services is not necessary. An e-commerce transaction may take place between businesses, households, individuals, governments and other private or public organisations. Tube included are orders made over the web, extranet or electronic data interchange. The type is defined by the method of placing the order. To be excluded are order made by telephone, facsimile or manually typed e-mail (OECD, 2011). Kalakos and whinstone (1997) refer to a series of different viewpoints for E-commerce:

1. A communications outlook - The dispensing of information, commodities or services electronically.

2. A business process outlook - The computerisation of business dealings and workloads.

3. A service outlook - enabling cost-cutting at the same time as increasing the speed and quality of service delivery. Cost reduction in activities as well as improving the speed and quality of service deliverance.

4. An online perspective - Online purchasing and sale of the products and details.

The U.K government also used a broad definition when explaining the scope of electronic commerce to industry:

E-commerce is the exchange of information across electronic networks, at any stage in the supply chain, whether within an organisation, between businesses, between businesses and consumers and consumers or between the public and private sector, whether paid or unpaid (cabinet office, 1999). These definitions reveal that the pre-sale and post-sale activities across the supply chain are part of e-commerce, and it is not entirely limited to the actual buying and selling of products. It is useful to recognise opportunities for buy-side and sell-side ecommerce transactions when determining the strategic effect of e-commerce on an organisation because structures with different functionalities would need to be developed in an organisation to facilitate transactions with buyers and sellers. Buy-side e-commerce refers to purchases from its vendors in order to acquire products that a company needs. Sell-side ecommerce refers to selling organisation's purchases.

\section{Different Types of Sell-Side E-commerce}

Sell-side eCommerce involves not only selling products but also using technologies to market services using a range of techniques. Not every product is appropriate for online sale, so the way a website is used to sell products varies. Consideration of the five key forms of online presence for sell-side e- commerce is beneficial, with each having different aims and is ideal for other markets. There are not straight cut categories of websites as these forms are mixed by businesses but with a shift of focus depending on the market they represent.

Transactional E-commerce sites: These allow for the online purchasing of items. The site 's key business activity is by selling certain goods.

1. The sites also help the company by offering information to customers who choose to purchase offline goods. These include shopping outlets, online banking services and travel websites.

2. Service-oriented relationship-building websitesprovide information to stimulate purchase and build relationships. Usually, the items are not available online for purchase. Information for informing purchasing decisions is given through the website and newsletters. The main contribution from the company is by promoting offline sales and attracting inquiries or leads from potential customers. These websites often bring value to current customers by offering resources to help them support them.

3. Brand building sites: Provide Brand Service Experience. Usually, the items are not available for purchase online. Their primary focus is to support the brand by developing an online experience of the brand. They are typical for low value, high volume fastmoving consumer goods (FMCG) brands for consumers.

4. Portal publisher or media sites- provide information, news or entertainment about a range of topics. "Portal" refers to a gateway of information. This is information on the web as well as through links to other pages. Portals have adversity of options for generating revenue, including advertising, commission-based sales and sale of customer data.

5. Social networks-social networks could be considered to be in the last category since they are often advertising-supported. Still, the influence of social networks such as Face book, Linked inn and Twitter on company and customer communications suggests they form a separate category.

Apart from the above definitions, there exist many other meanings from different perspectives. From an exchanges point of view, electronic commerce is the deliverance of information, goods or services or disbursement via telephone lines, computer networks or other electronic means from a business process angle. Electronic commerce is the function of technology automation of business dealings and work flows, from a service perspective. Electronic commerce is a method that tackles businesses, customers and management's ability to reduce service costs while enhancing product quality and increasing service delivery speeds from an online perspective. Electronic commerce is the medium through which companies, management and customers hope for a reduction in cost as well 
as improvement in the quality of goods and increasing the regularity of goods delivery. To the definitions mentioned above, it may be said that electronic commerce is a complex phenomenon for which there exist several definitions. Nevertheless, researchers agree that electronic commerce is a rising model which would enable consumers to initiate participation in all purchase decision perspectives, including a selection of items required for purchasing items securely and payments electronically. The electronic models are discussed below.

- Customer to Customer (C2C) model involves shopper directly communicating with other customers in the online platform. The customer to customer model is one of the significant models in Internet-based transactions'. Many researchers have asserted that electronic commerce has grown as can be seen by the growth of social networking sites.

- Business 2 Customer (B2C) This model is an interaction between company and customer through online medium. The information about products are available online, and customers prefer to buy online by making online payments. The goods are then delivered to them online or physically by post.

- Business to Business (B2B) The business to business model involves buying and selling of goods through the Internet. The turnover and profitability are enormous compared to other models which enable them to conduct business dependably.

- Customer to Business (C2B) This model is very much an equivalent of the $\mathrm{B} 2 \mathrm{C}$ model. This includes the online procurement and sale of products and services. It is a model in which consumer initiates transactions with companies

- Customer 2 Government (C2G) Sometimes online transactions are initiated whereby customers give feedback to the government through customer groups or individual sites.

- Business 2 Government $(B 2 G)$ is a type of online interaction where feedback from businesses is given to government and non-government organisations.

- Government 2 Citizen $(G 2 C)$ is a type of online interface through which government provides information's through communication such as local government services, public government services, general government Information and tax information. To improve small industries performance a basic understanding of electronic commerce models is necessary.

\section{Internet Marketing, E-Marketing and Online Marketing}

Internet marketing, online marketing and electronic marketing have different definitions among researchers. Internet marketing is used synonymously with online marketing. At the same time, online marketing is also called web marketing, electronic marketing, internet marketing etc. Many other researchers have termed E-marketing as broader than internet marketing as it includes Internet, World Wide Web and E-mails only. But E-marketing includes activities included in internet marketing as well as many other activities and tools.

\section{A. Social Media Marketing}

The social aspects of the Internet are evident in sites such as Face book, Twitter, Link inn, and YouTube have become critical components of companies' e-commerce efforts. The technique of social media marketing recognises that shoppers, especially young people, expect to play a proactive role in their shopping experience by writing and reading product reviews, asking questions, reading and writing blogs, watching and creating videos, posting comments and engaging in other interactive behaviours. Many small companies drive traffic to their website through their Face book, Pinterest and Instagram pages, Twitter posts and linked inn accounts. They use their websites as a hub supported by the spokes of social media. Websites that include an asocial sign-in feature, which allows social media users to bypass creating accounts and passwords when they log into a company's website and social media. Many small companies have discovered that social media provide an excellent platform for engaging and interacting with their customers and listening to what their customers are saying about their businesses, products and services. Scarborough and Cornwell (2016).

\section{B. Components of Digital Marketing Media}

The emergence of the Internet and the World Wide Web has been argued to fundamentally reshape economic conditions and business practices of firms. It is seen as a promoter of the rapid internationalisation of companies, particularly small and medium enterprises. (Rudolf R. Sinkovics. ElfriedePenz, 2006).

Chaffey et al. (2009) recommend six main types of digitalcommunications tools or channels that are reviewed by marketers for suitability for customer acquisition:

1. Search engine marketing (paid sponsored listings and the organic or natural results;

2. Online PR, including social media marketing;

3. Online partnerships, including affiliate marketing and aggregators such as price comparison sites;

4. Interactive advertising;

5. Opt-in e-mail marketing; and

6. Viral or word-of-mouth marketing in which social networking acts as a facilitator

Marketing can take many different forms in the digital world: for example, companies can use search engine advertising and optimization, electronic newsletters or banner advertising.' These are the most commonly used internet marketing practices, and Google and its Ad Word advertising optimization are among the most popular search engine advertising tools. It has also been seen that the influence of the traditional 
Marketing tools have lately diminished. Traditional one-way marketing has diminished in efficacy as consumers have become accustomed to digital and virtual marketer interactions. When marketers discovered that they could reach consumers through digital resources such as e-mail or social networks, they gathered a massive amount of customer data. That data can be addressable through the organised database and measured for customer profile building. The actions of each person --stop press, or contact - can be monitored with the digital channel. The more customers engage with the media, the greater the impact of (Laura Immonen and Jaakko Joensuu, 2009).

\section{Digital Marketing Tactics}

The proliferation of digital channels raises the question of which tactics companies should select. While acknowledging that the selection of tactics is guided by marketing strategy, the most actively used digital marketing channels are currently websites, e-mails and newsletters, and social networking services (SNSs) (Leeflang et al., 2014). Apart from the company website, which is a must-have for nearly all kinds of firms, there are considerable differences between industries about the use of other digital marketing tactics

Website:

Websites are an efficient way to display media, distribute information and provide solutions for shareholders and customers. If a website has regular and continuous interaction with its customers, it is already building a relationship. (Mika pyhamaki, 2012). According to Scarborough and Cornwall (2016), the following six factors are essential for achieving digital marketing success through websites.

\section{1) Acquiring customers}

The first digital marketing skill any entrepreneur must master is acquiring customers who require them to drive traffic to their website. The entrepreneur must develop a strategy for using the many available tools which range from display ads and Google ad words to social media and search marketing.

\section{2) Optimising conversions}

Every online entrepreneur's goal is to convert website visitors into paying customers. The efficiency with which an online company achieves this goal plays a significant role in determining its profitability. Unfortunately, more than $97 \%$ of visitors to the typical retail website do not purchase anything.

\section{3) Maximising website performance}

Once customers find a company's website, they should encounter a site that downloads quickly, is to navigate and contains meaningful content they can find quickly and efficiently. A fast, simple checkout process also is essential. Otherwise, customers will abandon the site, never to return.

4) Ensuring a positive user experience

Achieving customer satisfaction online is just as important as it is offline.

\section{5) Retaining customers}

Just as in the offline store, customer retention is essential to the success of online businesses. Entrepreneurs must create an online experience that engages customers, offers them value and provide them with.

6) Using Web analytics as part of a quality improvement cycle

The entrepreneur has a multitude of web analytics tools (many of them free) that they can use to analyses the performance and effectiveness of their websites.

\section{Conclusion}

The present paper analysed the various forms of digital marketing and its potential usage. It also covered the different concepts and theories used for understanding adoption. The other aspects discussed are about the E-marketplace and its functionalities to the adoption of digital marketing.

\section{References}

[1] A Nickles (2000), A wake-up call for security. Midrange Systems, vol. 13, No. 4, pp.52-54.

[2] B. Violin. (1996) The Biggest and Best Information, Volume. 9, No. 9, pp. 44-46.

[3] Charles worth, Alan (2015) An introduction to social media marketing. Taylor and Francis

[4] Davis, Fred D (1989) Perceived Usefulness, Perceived Ease of Use, and User Acceptance of Information Technology. MIS Quarterly, Volume. 13, (No. 3), Pp. 319-340

[5] Millard., Havlicek, J., Agric, I. Ticha. (2004) Good practices in Digital smes. Econ-Czech, Volume 50, Issue 1, pp. 13-19.

[6] Rudolf R. Sinkovics. Elfriede Penz (2006) Empowerment of SME websites - Development of a web empowerment scale and preliminary evidence. J Int Entrepr (3) pp. 303-315

[7] Setiowati, Rini Hartoyo., Heny. K. Daryanto and Bustananul Arifin (2005) The effects of ICT adoption on marketing capabilities and business performance of Indonesian SMEs in the fashion industry. Journal of business and retail management research, pp. 100-115.

[8] Tan, Jing, Tyler, Katherine and Manica, Andrea (2007) Business to Business adoption of ecommerce in China. Information and management, Volume 44, pp. 332-351.

[9] W. Mougayer, 1998, Opening Digital markets-battle plans \& strategies for internet commerce. 2nd edition, Commerce Netpress, Macgraw-hill

[10] Zhu Kevin and Kramaer, Kenneth L, (2005), Post adoption variations in usage and value of E-business by organisations: Cross country evidence from the retail industry. Information systems research, Volume 16, Issue 1, pp. 61-84. 